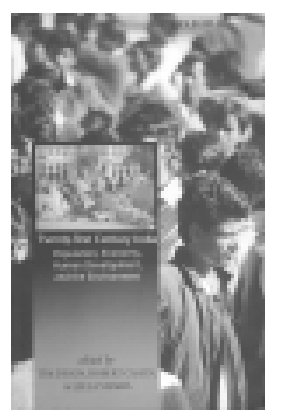

\title{
At the interface of environment and development: a tale of two treatises
}

\author{
Reviewed by Nilanjan Ghosh \\ Souvik Bhattacharjya
}

Resources, Energy, and Development 3(2): 55-56

1 Dyson T, Cassen R, and Visaria L (eds). 2004

Twenty-first century India: population, economy, human development and the environment

New Delhi: Oxford University Press

2 Sengupta R and Sinha A K (eds). 2003

Challenge of sustainable development: the Indian dynamics

Kolkata and New Delhi: CDEP and Manak

What lies at the interface of environment and development? How and what types of social and demographic forces determine the interactions of environment and development in developing nations? These critical concerns have been haunting developmental discourse over the last two decades. Even more critical is the concern of how such forces would unfold themselves in the years to come. The two books, Twenty-first century India: population, economy, human development and the environment and Challenge of sustainable development: the Indian dynamics, are treatises on how socioeconomic and demographic forces unfold in India, and how they impinge on the interactive dynamics of environment and development. The commonalities in these two volumes emerge broadly from the motivation with which they have been initiated.
Twenty-first century India provides an integrated account of the impact of India's population on development and environment, eventually providing an analysis of the potential impact of population growth on the country's future. Using a variety of modelling and analytical tools, the authors study historical empirical information on India's population and make projections about future trends in fertility, mortality, and urbanization. It has been found that growing numbers do complicate the task of achieving widespread education and contribute to poverty with increasing divergence in social conditions among the states. The rapid increase in the labour force has serious adverse consequences for employment. The book is reasonably optimistic about India's food prospects: the country can continue to feed itself. It can also enjoy higher levels of energy use, manufacturing, and modern forms of transport with less chemical pollution. Consequently, India's cities can become cleaner and healthier places to live in, though good management of water as a resource will continue to be a serious challenge, and one most strongly related to population growth. The analysis builds on new projections fifty years from the Census of 2001, by which time India's population had already passed the 1 billion mark. Twenty-five years later it is expected to exceed 1.4 billion, 
and will almost certainly pass 1.5 billion by midcentury. The authors contend that India's future problems are large, but in principle, manageable. In this context, the book examines the challenges ahead, outlines policies, and identifies lacunae in their implementation, which lie at the root of most of the difficulties facing the nation today.

After providing an overview, the volume sets in motion with Tim Dyson's chapter on India's population. While the demographic issues have more or less been comprehensively dealt with in this chapter, the lack of allusion of issues like changing demographics and its future consequences makes the analysis incomplete. If the young people newly entering the labour force can find jobs, this may be beneficial in the short-run, but their smaller numbers could present a major problem in the next 40 years if adequate plans are not made to care for an increasingly large old-age population. While statistics on India's population for 2001 have been presented in tables, they have not been sufficiently used in texts.

Leela Visaria, dealing with mortality and health transitions, has provided an informative analytical base, but there is the relative lack of attention to historical literature-for instance, by McArthur and Sachs (2001) on disease conditions and colonial health interventions.

The chapter by Dyson and late the Pravin Visaria on migration and urbanization is interesting. It is predicted that about half of India's population will be living in urban areas by 2026 , but the rate of urban population growth will continue to fall over that period because of declining urban birth rates. Another prediction made is that urban growth is most likely to occur in places that have good transportation links (apart from big cities). Growth in urban population will come not so much from rural-to-urban migration, but more from relocation of people from smaller urban centres to larger ones.

Geeta Gandhi Kingdon and co-authors link education and population trends, examining the impact of literacy on population growth and describing the challenges the educational system faced in satisfying the demand from upcoming cohorts. An extensive discussion of the famous PROBE (Public Report on Basic Education) highlights the constraints in delivering good public schooling that have led to a sharp rise in the numbers of private schools, especially in some poorly performing states like Uttar Pradesh. Chapters on employment by Kirsty McNay, Jeemol Unni, and Robert Cassen conclude that with a 50\% increase in the working-age population by 2026 , it is expected that there will be a significant worsening of India's employment situation.

Cassen and McNay's chapter titled The condition of the people looks at the fundamentally important topic of poverty and well-being. In today's understanding, poverty is not just a lack of income, but includes deprivation in health, education, and other aspects of well-being. Only two indicators have shown accelerated improvement in the last decade-fertility decline and education, although nearly one-third of the population is illiterate. An important debate has been highlighted whether poverty and inequality increased or decreased in the 1990s, and by how much. The debate is more centered on an error by the Indian NSS (National Sample Survey) that arbitrarily changed the method by which expenditure data was collected in 1999/2000, creating a series that was inconsistent with previous rounds.

Shankar Acharya's chapter titled The economy-past and future with Cassen and McNay is dated. It offers a summary of past trends in growth rates and of the policies that led to the surge in India's economic growth in the early 1990s. This can be found in any textbook at the undergraduate level that deals with the Indian economy. The chapter has discussed the factors leading to economic growth in detail, without concentrating much on the performance of the external sector, which has played a pivotal role in the recent past and will continue in the future. 
The chapter Prospects for food supply and demand by Amresh Hanchate and Dyson predicts, 'There will be no radical transformation of India's food situation.' However complications in modelling food demand and supply, makes the chapter very much speculative.

The chapter Modelling the environment by Dennis Anderson reports the findings from an econometric simulation model of future trends in environmental pollution and energy use. There has been presentation of significant literature with findings but the chapter fails to describe the methodologies being adopted by the literature (at least some) to arrive at those findings. Anderson has admitted serious inadequacies in data quality but uses the data in a dynamic general equilibrium model with endogenous energy pricing. This then produces precise simulations of the trends in emissions. However, data inadequacies should have been built into the model so that the various simulations could have come with confidence intervals.

Chapters on the urban environment, water, and common-pool resources have, to a good extent, highlighted the current situation. The chapter on demand for water is pessimistic. On the urban environment, the problem is largely one of governance and a lack of the public's appreciation for environmental problems. The chapter on CPRs (common-pool resources) argues that instead of viewing CPRs as safety nets that prevent people from falling into deprivation, there is a need for a wider focus, including market-based opportunities for their role in the provision of ecological services.

\section{Challenge of sustainable development is}

the outcome of the symposium held at the Indian Institute of Management, Calcutta in February 2001. The volume has been compiled in the backdrop of the 2001 Census, with a focus on population trends. Vital questions regarding factors related to food security, provision of health services, and the increased need for urban space were raised and discussed. The contributors are renowned Indian scholars, dealing with various facets of the developmental discourse in the Indian context. The introductory chapter by the editors, Ramprasad Sengupta and Anup Sinha, both economists, sets the mood for the analysis to appear in the next few pages. There is not much to comment on the papers, which have been, on the whole, of high quality, and provide valuable insights to the concerns related to population, water, land, health, education, and urban space. Each of the issues concerns itself with two chapters from two Indian stalwarts in the field.

Chapters 2 and 3 are devoted to the concerns of population, authored by Ashish Bose and Gita Sen, respectively. From a demographer of Bose's stature, of course, one would expect a much more objective and critical analysis of the existing demographic trends than is presented. While he has concerned himself with the methodology of development of human misery index, the sudden allusion on the role of women in life support in the Himalayan villages in Uttaranchal seems a bit out of place and does not fit into the analysis. Sen's paper is tighter in this respect. Sen talks of the new demographic paradigms to answer some age-old concerns, and quite ably puts that in the context of the Indian policy framework.

The following two chapters are on water. Jayanta Bandyopadhyay and Bidisha Mallik's chapter, identifying the crucial knowledge gaps in water use in India, presents a water balance account of India in terms of the economy's water demand and supply. While certain policy perscriptions have been forwarded on the note of the changing paradigm of water resource management, the data analyses part could have been made stronger with the help of an ecological economist or an econometrician. This could have rendered a better dimension to the paper. On a comparative note, Vaidyanathan's paper, Water resource development: scarcity and conflict is loose and outdated. That 'scarcity induces conflicts' is an age-old hypothesis, and the interest on reinforcing on the same has long been lost - as stressed by Bandyopadhyay 
(2004) and Ghosh (forthcoming) - they need to be looked at from the perspective of the new emerging paradigm of water resource management, and not from the perspective of the old paradigm of water resource development.

Food security is a prime concern of development, and is quite loosely dealt with by C L Acharya and A K Sharma. While their bias towards technical details is quite expected due to their background in natural sciences, there is a lack of crucial institutional economic perspectives and focus on issues pertaining to land reforms, distribution, role of pricing mechanisms, and impact assessments. Utsa Patnaik has presented her analyses on food and land use on a broader scale of sustainable development in the context of global consumption demands. The article makes a strong statement that exports should not happen at the cost of food security. Such a statement, though debatable, has long-term implications in terms of natural resource use.

The health section, encompassing chapters by N H Antia and Debabar Banerji, is the weakest link in the entire volume. The chapters are verbose and repetitive, and the analyses are dated. The two papers on education by veteran economist, Tapas Majumdar, and econometrician, V N Reddy, encompass two different types of analyses. Majumdar has provided detailed analyses of the investment patterns in the education sector in India, and has propositions for its future. Reddy's analysis on the constraints and prospects of the universalization of elementary education is rigorous. There is little to comment on the last two chapters on urban space and infrastructure by Annapurna Shaw and Amitabh Kundu, except that they are sound in terms of structure and content, thereby rendering a new dimension to the volume.

On a comparative note, the volumes have their own strengths and weaknesses. Twentyfirst century India uses much more updated information with respect to the databases of the Indian economy, including the 2001 Census and the 55th round NSS, while Challenge of sustainable development stops at the 1991 Census and the 53rd round of NSS. Challenge of sustainable development provokes thoughts in the readers' minds regarding the challenges that India is about to face in the context of changing socio-economic-ecological dynamics. Twentyfirst century India takes a much more futuristic view of the Indian socio-economic scenario, and presents the picture on the trajectories of the various variables, under various types of reigning forces. Editors of both volumes deserve congratulation for their attempts to create a pathway to reconcile between the various challenges that the Indian economic and social system will face in the years to come.

\section{References}

McArthur J W and Sachs J D. 2001

Institutions and Geography

NBER Working Paper 8114, February

Ghosh N. Forthcoming

A scarcity value based explanation of transboundary water disputes in water scarce economies: a tale of two river basins

Kolkata: Centre for Development and Environment Policy

Bandyopadhyay, J. 2004

\section{Adoption of a new and holistic paradigm is a pre-condition for integrated water management in India}

In Water security and management of water resources edited by G Saha

Kolkata: National Atlas and Thematic Mapping Organization 